\title{
Retrospective and prospective study of septoplasty and septoplasty with F.E.S.S in chronic nasal obstruction with effect on blood pressure
}

\author{
Jagram Verma ${ }^{1, *}$, Alka Chouhan ${ }^{2}$ \\ ${ }^{1}$ Associate Professor, ${ }^{, 2} \mathrm{III}^{\mathrm{rd}}$ Year Resident, ${ }^{1,2}$ Dept. of ENT, ${ }^{1,2}$ Mahatma Gandhi Memorial Medical College, Indore, Madhya Pradesh, India
}

*Corresponding Author: Jagram Verma

Email: chouhanalka1@gmail.com

\begin{abstract}
Aim: To assess the efficacy of septoplasty and septoplasty with fess in patients with chronic nasal obstruction in correlation with blood pressure.

Materials and Methods: A Study was conducted at Mahatama Gandhi Memorial Medical College \& Maharaja Yeshwantrao Hospital, Indore A Total of 100 patients retrospectively \& prospectively were taken who underwent Clinical, Diagnostic Nasal endoscopy, Computed Tomography, Blood Pressure evaluation \&surgical intervention (septoplasty \& septoplasty +F.E.S.S).

Results: Total of 100 patients were taken out of which 53 were males \& 47 were females. Under Group A patients undergoing septoplasty were placed were $60 \%$, in group B patients undergoing septoplasty with fess were placed which were $40 \%$. patients showed that $80 \%$ cases of group A and $87 \%$ of group B were relieved of nasal obstruction. Post op blood pressure changes were significantly reduced in age group 21-30 Years.

Conclusion: Septoplasty \& Septoplasty+ F.E.S.S can be used as operative tool in reducing elevated blood pressure in patients with chronic nasal obstruction.
\end{abstract}

Keywords: Nasal obstruction, Septoplasty, Surgery.

\section{Introduction}

The nose is primarily an airway. More specifically, it is a pair of airways, which as a result of their structure, assist additional functions of the nose such as humidification, cleaning and olfaction.

The first anatomical description of nose was given by Berengario da Carpi et al. ${ }^{1}$ (pseudonym of Jacopo Barigazzi, 1466 - 1530), Nasal obstruction is the most common complaint in rhinologic practice and a deviated nasal septum is the most common cause of nasal obstruction. The evaluation of septal deviation causing nasal obstruction depends heavily on physical examination and imaging (Dinis \& Haider, 2002). ${ }^{2}$ Other causes for nasal obstruction includes Chronic rhinosinusitis with or without polyposis.

After Egyptians, ancient Greek physicians, like Hippocrates, Galen, and Celsus et al. ${ }^{3}$ may have also recognized the paranasal sinuses as part of the structure of the skull. Specifically, Hippocrates, in his writings, gave instructions on how to treat nasal polyps. Johann von Mikulicz-Radecki et al. (1886) ${ }^{4}$ he was the first surgeon who introduced the concept of antrostomy.

The nose normally accounts for approximately half of the respiratory resistance to airflow and the nasal valve is responsible for at least half of the nasal resistance to airflow. Nasal septum deviation is one of the most frequent reasons for nasal obstruction presented with a reduction in nasal airflow and chronic mucosal irritation. This condition increases upper airway resistance and has been shown to decrease oxygen saturation and increase the arterial carbon dioxide content. The response to hypoxia and hypercarbia is vasoconstriction induced arterial resistance. Burnum JF, Hickam JB, McIntosh HD et al.(1995). ${ }^{5}$ Thus abnormal upper airway resistance can play a role in the development of hypertension
The effect of nasal obstruction on cardiac system has not been precisely investigated it has been shown in literature Various studies has been done on the effect of chronic upper respiratory obstruction such as hypertrophied tonsils, adenoid vegetation and nasal polyposis on cardiopulmonary system.

This study was therefore undertaken with the aims of evaluating the effect of septoplasty \& septoplasty with F.E.S.S on the BP of patients with nasal obstruction, and to assess whether a positive association exists between deviated nasal septum and Blood pressure.

\section{Materials and Methods}

The present study, carried out in the Department of Otorhinolaryngology, M.G.M. Medical College and M.Y. Hospital, Indore (M.P.), a total of 100 patients with complaints of nasal obstruction \& clinical evidence of chronic rhinosinusitis were evaluated with Nasal endoscopy and CT scan PNS coronal view from March. 2015 to March. 2018. The cases for study were selected from E.N.T outpatient department with clinical evidence of chronic rhinosinusitis for more than 6 months,

Not responding to medical treatment, subjected to detailed history with presenting complaints like nasal obstruction (its duration, whether it is continuous or intermittent and whether it is associated with any external nasal deformity) were evaluated and a diagnosis was made, facial pain, headache, nasal discharge, postnasal discharge, sneezing, episodes, acute, chronic or serous otitis media. In addition complete personal, past and family history with past medical/surgical history were taken.

complete clinical examination of patients was done anterior rhinoscopy, posterior rhinoscopy. Pre op CT P.N.S, nasal endoscopy were done for further evaluation. 
Patients with inflamed maxillary, ethmoidal sinuses \& DNS were managed with septoplasty \& extensive disease of osteomeatal complex were managed with septoplasty \& FESS. 100 of cases were taken, they were divided into group A and group B, with 60 cases in Group A who underwent septoplasty and 40 cases in Group B who underwent Septoplasty with F.E.S.S.

Mean of Three consecutives blood pressure were taken pre-operatively, intraoperatively, \&postoperatively. Regular Follow up of patients till 3 months were taken in OPD.

\section{Results}

In our study 100 patients were divided into two groups according to their operative management., Under Group A patients undergoing septoplasty were placed were $60 \%$,in group B patients undergoing septoplasty with fess were placed which were $40 \%$.In group A highest number of patients belonged to age group 21-30 years (21). Followed by $31-40$ years (20), \& least belonged to age above 50(4). In group $\mathrm{B}$ highest number of patients belonged to age group 31-40 years (12). Followed by age group21-30 (10). Least being in group more than 50 .

No. of Patients Total no. of 100 patients were taken out of which $53 \%$ were males $47 \%$ were females. M:F ratio $=1.12: 1$

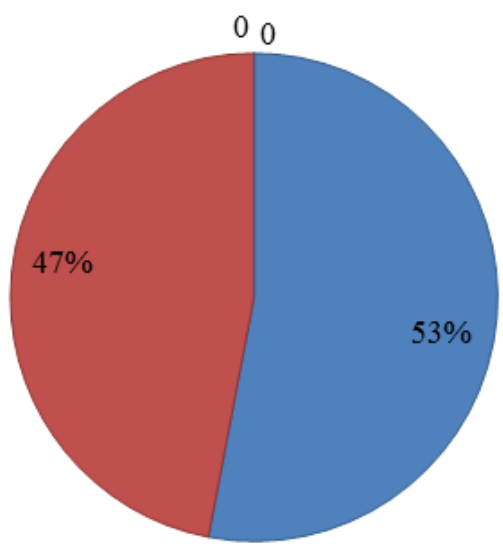

Males

-Females

Fig. 1:

Pathological changes detected on CT PNS most common finding was Concha bullosa (65\%), followed by, inferior turbinate hypertrophy $(60 \%)$, among sinus most Common sinus involved was maxillary $(50 \%)$

Table 1: Pathological changes detected on computer tomography

\begin{tabular}{|l|c|c|}
\hline \multicolumn{1}{|c|}{ Findings } & No. of Patients & \% \\
\hline Inferior Turbinate Hypertrophy & 60 & 60 \\
\hline Concha Bullosa & 65 & 65 \\
\hline Polyp & 40 & 40 \\
Antrochoanal & 25 & 25 \\
Ethmoidal & 15 & 15 \\
\hline Anterior Ethmoids & 40 & 40 \\
\hline Posterior Ethmoids & 30 & 30 \\
\hline
\end{tabular}

\begin{tabular}{|l|l|l|}
\hline Maxillary & 50 & 50 \\
\hline Frontal & 28 & 28 \\
\hline Sphenoid & 25 & 25 \\
\hline
\end{tabular}

Postoperative follow up of the patients showed that $80 \%$ cases of group A and $87 \%$ of group B were relieved of nasal obstruction while headache was relieved in $58 \%$ of Group A and $75 \%$ of group B. There was no relief from epistaxis in group A while it was relieved in $10 \%$ of patients of group B.

Residual deformity along with synechiae was most common post op complication In group A, While bleeding was most common complication in Group B.

Table 2: Comparisons of post relieved post-operatively

\begin{tabular}{|c|c|c|}
\hline Complications & Group A & Group B \\
\hline Bleeding & $3 / 60(5 \%)$ & $5 / 40(12.5 \%)$ \\
\hline Synechiae & $6 / 60(10 \%)$ & $3 / 40(7.5 \%)$ \\
\hline Residual Deformity & $6 / 60(10 \%)$ & $2 / 40(5 \%)$ \\
\hline Septal Haematoma & $1 / 60(1.6 \%)$ & $2 / 40(5 \%)$ \\
\hline Septal Perforation & $1 / 60(1.6 \%)$ & $1 / 40(2.5 \%)$ \\
\hline Parasthesia & $2 / 60(3.3 \%)$ & $3 / 40(7.5 \%)$ \\
\hline
\end{tabular}

Table 3: Frequency of symptoms operative complications

\begin{tabular}{|l|c|c|}
\hline $\begin{array}{l}\text { Symptoms } \\
\text { Relived }\end{array}$ & $\begin{array}{c}\text { Group A } \\
\text { (p/0 Septoplasty) }\end{array}$ & $\begin{array}{c}\text { Group B } \\
\text { (p/o Septoplasty + } \\
\text { FESS) }\end{array}$ \\
\hline $\begin{array}{l}\text { Nasal } \\
\text { Obstruction }\end{array}$ & $48(80 \%)$ & $35(87 \%)$ \\
\hline Rhinorrhea & $40(66.6 \%)$ & $30(75 \%)$ \\
\hline Headache & $35(58 \%)$ & $30(75 \%)$ \\
\hline Epistaxis & $10(16.6 \%)$ & $10(25 \%)$ \\
\hline
\end{tabular}

Post op blood pressure changes were significantly reduced in age group 21-30 Years, while there was no significant change post op blood pressure IN age group 4150 Years.

Table 4: Age wise post-operative blood pressure distribution

\begin{tabular}{|c|c|c|c|}
\hline Age & Decrease & Increase & $\begin{array}{c}\text { No } \\
\text { Change }\end{array}$ \\
\hline $21-30$ years & 82 & 2 & 18 \\
\hline $31-40$ years & 78 & 15 & 7 \\
\hline 41-50 years & 25 & 20 & 55 \\
\hline
\end{tabular}

\section{Discussion}

Study conducted by Mundra et al in $2014^{6}$ had a total of 61 patients 34 were male and 27 were female and majority were in the age group of 21-40 years,

Clinically, nasal discharge seen in $80.33 \%$ cases was predominantly bilateral and mucoid in nature. Nasal obstruction was seen in $78.69 \%$ cases and DNS was predominantly on left $(59.01 \%)$ side. Shrivastava et 
al. $(2015)^{7}$ observed in his patients the chief presenting symptoms were nasal discharge in $96.25 \%$ cases

Smitha et al. $(2016)^{8}$ observed $92 \%$ presented with complaints of nasal discharge, $80 \%$ patients presented with nasal obstruction, Verma et al.(2016) ${ }^{9}$ observed most common symptom was nasal obstruction $(81 \%)$, followed by nasal discharge $(66 \%)$ headache. In study by Goel et al. CT PNS showed OMC obstruction was the most common finding in $39(97.5 \%)$ patients. Mucosal hypertrophy of maxillary sinus was the next most common finding in 28 (70\%) patients. In our study of CT PNS showed DNS to right in 60\% Inferior turbinate hypertrophy in $60 \%$ of cases, concha bullosa in $65 \%$ uncinate medialized in $40 \%$, haller cells found in 23\%, Agger nasi in 13\% polypoidal mucosa in $40 \%$ of cases, Mucosal thickening of maxillary sinus being the most common site of involvement $50 \%$, followed by anterior ethmoids in $20 \%$, posterior ethmoids $15 \%$, frontal in $10 \%$, sphenoid sinus $8 \%$. In a study by Smitha et al. significant association $(\mathrm{p}<0.0001)$ was found between blood pressure \& septal correction. Our study concluded $82 \%$ showed significant decrease in blood pressure belonging to 20-30 years, therefore concluding septoplasty $\&$ FESS can be used as surgical modality for controlling blood pressure in patients with chronic rhino sinusitis.

\section{Conclusion}

Chronic nasal obstruction is most common symptom for sinonasal disease. Most commonly seen in chronic rhino sinusitis which is chronic inflammation of nasal mucosa and sinuses.

Septoplasty with fess is effective in treatment of chronic nasal obstruction in cases with or without polyp. It is not only used for septal correction but also completely removes diseases from sinuses. Where as septoplasty alone is effective for nasal obstruction with septal deviation.
Septoplasty alone or with FESS is an excellent tool for controlling blood pressure in patients with chronic nasal obstruction.

\section{Conflict of Interest: None.}

\section{References}

1. Berengario da Carpi, Jacopo (1530). Isagogae breues et exactissimae in anatomia humani corporis.

2. Dinis PB, Haider H: Septoplasty- Long term evaluation of results. Am J Otolaryngol 2002;23(2):85-90.

3. Hippocrates. Collected writings Vol. 4 Athens: Cactus; 1992.

4. Johann von Mikulicz-Radecki. Annals of Surgery: November 1860;152(5):923-926

5. Burnum JF, Hickam JB, McIntosh HD. The effect of hypocapnia on arterial blood pressure. Circ 1995;9(1):89-95. doi: 10.1161/01.CIR.9.1.89.

6. R. K. Mundra, Yamini Gupta, Richi Sinha, and Alaknanda Gupta: CT Scan Study of Influence of Septal Angle Deviation on Lateral Nasal Wall in Patients of Chronic Rhinosinusitis. Indian J Otolaryngol Head Neck Surg 2014;66(2):187-190.

7. Mohit Srivastava, Sushant Tyagi, Radhika Chaudhary, Lalit Kumar, Role of Functional Endoscopic Sinus Surgery in Sinonasal Diseases: A Case Study and Review of Literature: Int J Sci Study 2015;3(9);18-19.

8. S. G. Smitha, B. Jagannath, and Amrita Suzanne Mathew: Impact of Septal Correction on the Blood Pressure of Hypertensive Patients with Deviated Nasal Septum; Indian J Otolaryngol Head Neck Surg 2016r;68(1):46-51.

9. Jagram Verma, Shiv Kumar Rathaur, Sanjeev Mishra, A.K. Mishra; The role of diagnostic imaging in evaluation of nasal and paranasal sinus pathologies, Int J Otolaryngol Head Neck Surg 2016;2(3).

How to cite this article: Verma J, Chouhan A, Retrospective and prospective study of septoplasty and septoplasty with F.E.S.S in chronic nasal obstruction with effect on blood pressure. Indian J Anat Surg Head Neck Brain 2018;5(1):31-33. 